\title{
Effects of curcumin on bleomycin-induced oxidative stress in malignant testicular germ cell tumors
}

\author{
AYSEGUL CORT, EVRIM OZDEMIR, MUJGAN TIMUR and TOMRIS OZBEN \\ Department of Biochemistry, Faculty of Medicine, Akdeniz University, Antalya 07070, Turkey
}

Received March 5, 2012; Accepted July 7, 2012

DOI: $10.3892 / \mathrm{mmr} .2012 .991$

\begin{abstract}
Bleomycin is commonly used in the treatment of testicular cancer. Bleomycin generates oxygen radicals, induces the oxidative cleavage of DNA strands and induces cancer cell apoptosis. Curcumin (diferuloylmethane) is a potent antioxidant and chief component of the spice turmeric. No study investigating the effects of curcumin on intrinsic and bleomycin-induced oxidative stress in testicular germ cell tumors has been reported in the literature. For this reason, the present study aimed to examine the effects of curcumin on oxidative stress produced in wild-type NTera-2 and p53-mutant NCCIT testicular cancer cells incubated with bleomycin and the results were compared with cells treated with $\mathrm{H}_{2} \mathrm{O}_{2}$ which directly produces oxidative stress. The protein carbonyl content, thiobarbituric acid reactive substances (TBARS), glutathione (GSH), 8-isoprostane, lipid hydroperoxide (LPO) levels and total antioxidant capacity in the two testicular cancer cell lines were determined. Results showed that bleomycin and $\mathrm{H}_{2} \mathrm{O}_{2}$ significantly increased protein carbonyl, TBARS, 8-isoprostane and LPO levels in the NTera-2 and NCCIT cell lines. Bleomycin and $\mathrm{H}_{2} \mathrm{O}_{2}$ significantly decreased the antioxidant capacity and GSH levels in NTera-2 cells. Curcumin significantly decreased LPO, 8-isoprostane and protein carbonyl content, and TBARS levels increased in cells treated with bleomycin and $\mathrm{H}_{2} \mathrm{O}_{2}$. Curcumin enhanced GSH levels and the antioxidant capacity of NTera-2 cells. In conclusion, curcumin inhibits bleomycin and $\mathrm{H}_{2} \mathrm{O}_{2}$-induced oxidative stress in human testicular cancer cells.
\end{abstract}

\section{Introduction}

Testicular germ cell tumors tend to affect young males, representing the most common tumor in males aged from 20 to 40 years and the incidence has been on the increase over the

Correspondence to: Professor Tomris Ozben, Department of Biochemistry, Akdeniz University, Faculty of Medicine, Dumlupinar Blv., Antalya 07070, Turkey

E-mail: ozben@akdeniz.edu.tr

Key words: bleomycin, curcumin, oxidative stress, reactive oxygen species, testicular cancer last decades (1). Bleomycin has been approved by the FDA to be used alone or with other drugs as a palliative treatment of testicular cancer. Bleomycin is used in combination with etoposide and cisplatinum (BEP therapy) for the treatment of adult and childhood testicular germ cell tumors. It is known that drug combinations usually work with greater efficacy compared with monotherapy since different drugs kill cancer cells in different ways. In our study, we did not use BEP, but applied bleomycin alone as our aim was to investigate the mechanism of action of bleomycin. Bleomycin is an essential component of the cisplatin-based chemotherapy regimens used effectively in the treatment of testicular cancer (2). Bleomycin generates oxygen radicals via its ferrous binding site, and induces the oxidative cleavage of DNA strands and cancer cell apoptosis (3). Bleomycin induces a high level of oxidative stress. This is due to the unique ability of bleomycin to generate reactive oxygen species (ROS) in mitochondria. One of its effects is breaking the DNA double helix via the production of free radicals, a process that is oxygen and iron-dependent. Bleomycin forms complexes with iron that reduce molecular oxygen to superoxide and hydroxyl radicals which cause single- and double-stranded breaks in DNA. Moreover, these ROS induce lipid peroxidation, carbohydrate oxidation and alterations in prostaglandin synthesis and degradation.

Numerous in vitro studies (4-6) have demonstrated that a wide range of anticancer agents induce programmed cell death (apoptosis) in malignant cells by generating ROS which is an important therapeutic interventional approach in cancer. Oxidative stress has been shown to decrease the $\mathrm{LD}_{50}$ (lethal dose that kills $50 \%$ of cells) of several types of antineoplastic agents and induce cancer cell apoptosis. ROS are essential for life due to their role in numerous vital processes, including normal mitochondrial metabolism, signal transduction and the bactericidal activity of phagocytes. These molecules are formed in vivo via oxidation-reduction reactions. ROS includes free radicals, such as hydroxyl and superoxide radicals, and non-radicals, including $\mathrm{H}_{2} \mathrm{O}_{2}$ and singlet oxygen (7). Hydrogen peroxide yields the highly toxic hydroxyl radical $\left({ }^{\circ} \mathrm{OH}\right)$ in the presence of reduced iron or copper via Fenton or Haber-Weiss reactions. Hydrogen peroxide easily diffuses into and out of the cells, and modulates cell proliferation, signal transduction pathways, gene expression and induces DNA damage, apoptosis and necrosis $(8,9)$.

There is an intense debate on the concurrent use of antioxidants during conventional cancer treatments. This 
argument is based on the fact that some chemotherapy drugs generate ROS which may kill cancer cells by inducing apoptosis. The induction of apoptosis via ROS is potentially an alternative mechanism for the cytotoxic effect of chemotherapeutic agents. It has been suggested that antioxidants prevent cancer cell death from ROS by inhibiting ROS and preventing ROS-induced apoptosis (7). Studies in the literature investigating the effects of various antioxidants on ROS-induced apoptosis in cancer are available $(10,11)$. So far, only three antioxidants, NAC with cisplatinum and doxorubicin, tangeretin with tamoxifen, and $\beta$-carotene with 5-fluorouracil have been shown to decrease the effectiveness of conventional cancer therapy in vivo $(12,13)$.

Curcumin (diferuloylmethane) is the chief component of the spice turmeric and is isolated from Curcuma longa. Curcumin is responsible for the yellow color of the spice as well as the majority of turmeric's therapeutic effects (14). The effects of curcumin have been investigated in other cancer cell types, but not in germ cell tumors. Although curcumin has been demonstrated to have anticancer activities both in vitro in numerous cancer cell lines and in vivo models, no study has been performed investigating the effects of curcumin on oxidative stress in testicular germ cell tumors. For this reason, we studied effects of curcumin on oxidative stress in NTera-2 and NCCIT testicular cancer cells (intrinsic) incubated with curcumin alone or in combination with bleomycin, and compared these results with oxidative stress generated by incubation with $\mathrm{H}_{2} \mathrm{O}_{2}$. We determined the levels of oxidative stress markers including protein carbonyl content, thiobarbituric acid reactive substances (TBARS), glutathione (GSH), 8-isoprostane, lipid hydroperoxide (LPO) levels and total antioxidant capacity in two testicular cancer cell lines incubated with curcumin, bleomycin, bleomycin+curcumin, $\mathrm{H}_{2} \mathrm{O}_{2}$ and $\mathrm{H}_{2} \mathrm{O}_{2}$ +curcumin.

\section{Materials and methods}

Cell lines. NTera-2 and NCCIT cells were obtained from the American Type Culture Collection (Manassas, VA, USA). NTera-2 and NCCIT cells were grown to confluence at $37^{\circ} \mathrm{C}$ in a humidified atmosphere containing $5 \% \mathrm{CO}_{2}$ in air in DMEM and RPMI medium, respectively, supplemented with $10 \%$ fetal bovine serum, $100 \mathrm{IU} / \mathrm{ml}$ penicilin and $10 \mu \mathrm{g} / \mathrm{ml}$ streptomycin (Invitrogen, Carlsbad, CA, USA). Results of our previous experiments (15), showed the $\mathrm{LD}_{50}$ of $\mathrm{H}_{2} \mathrm{O}_{2}$ (Sigma, St. Louis, MO, USA) on NCCIT cell viability to be $35 \mu \mathrm{M}$, for bleomycin (Nippon Kayaku, Co., Ltd., Tokyo, Japan) as $120 \mu \mathrm{g} / \mathrm{ml}$ and for curcumin (Sigma) as $5 \mu \mathrm{M}$. Moreover, we determined $\mathrm{LD}_{50}$ of curcumin on NTera- 2 cell viability as $20 \mu \mathrm{M}$, for bleomycin as $20 \mu \mathrm{g} / \mathrm{ml}$, and for $\mathrm{H}_{2} \mathrm{O}_{2}$ as $400 \mu \mathrm{M}$ (15). We applied these doses in the incubations.

8-Isoprostane assay. As a measure of cellular oxidation, the 8-epi-prostaglandin $\mathrm{F}_{2 \alpha}$ level was measured in $100 \mu \mathrm{l}$ samples of cell culture media using an enzyme immunoassay kit (Cat. \#516351 Cayman Chemical, Ann Arbor, MI, USA) according to the manufacturer's instructions. A standard curve utilizing authentic 8-epi-prostaglandin $\mathrm{F}_{2 \alpha}$ standard was prepared and values for 8-epi-prostaglandin $\mathrm{F}_{2 \alpha}$ were reported as $\mathrm{pg} / \mathrm{ml}$ of media.
TBARS assay. Lipid peroxidation was determined measuring TBARS using the TBARS assay kit (Cat. \#10009055 Cayman Chemical), according to the manufacturer's instructions. Cell suspensions were centrifuged at 1,000 rpm for $5 \mathrm{~min}$ and washed twice with phosphate-buffered saline (PBS). Supernatants were discarded and cell pellets were resuspended in $1 \mathrm{ml}$ PBS and sonicated using an ultrasonic processor three times for 5 -sec intervals at the $40 \mathrm{~V}$ setting over ice. TBARS levels are expressed as $\mathrm{nmol} / \mathrm{ml}$.

GSH assay. Cells were scraped and collected by centrifugation. The cell pellet was resuspended in $1 \mathrm{ml}$ of PBS containing $1 \mathrm{mM}$ ethylenediaminetetraacetic acid (EDTA) and sonicated using an ultrasonic processor three times for 5-sec intervals at the $40 \mathrm{~V}$ setting over ice. The supernatant was deproteinized using 10\% metaphosphoric acid (Sigma) and collected to determine total GSH levels according to the manufacturer's instructions (Cat. \#703002 Cayman Chemical). The total GSH levels were expressed as $\mathrm{nmol} / \mathrm{mg}$ of protein.

Protein carbonyl assay. Protein-bound carbonyl levels were measured using a protein carbonyl assay kit (Cat. \#1005020 Cayman Chemical). The method was based on the covalent reaction of the carbonylated protein side chain with 2,4-dinitrophenylhydrazine (DNPH) and detection of the protein-hydrazone product at an absorbance of $370 \mathrm{~nm}$. The results were calculated using the extinction coefficient of $22 \mathrm{M}^{-1} \mathrm{~cm}^{-1}$ for aliphatic hydrazones and were expressed as a $\mathrm{nmol} / \mathrm{mg}$ protein.

Total antioxidant capacity assay. The total antioxidant status in cell culture lysates was determined using the commercial total antioxidant assay kit (Cat. \#709001 Cayman Chemical) according to the manufacturer's instructions. The assay relies on the ability of antioxidants present in the samples to inhibit the oxidation of ABTS [2,2'-azino-di-(3-ethylbenzthiazoline sulfonate)] to $\mathrm{ABTS}^{\bullet+}$. The amount of $\mathrm{ABTS}^{\bullet+}$ produced is monitored by reading the absorbance at $405 \mathrm{~nm}$. Total antioxidant capacity levels were expressed in $\mathrm{mM}$.

LPO assay. The LPO assay measures hydroperoxides in isolated lipid-phase of samples directly following ferrous ion reduction. This assay was performed using the LPO kit (Cat. \#705003 Cayman Chemical Company). LPO levels were expressed in $\mathrm{nM}$.

Statistical analysis. Data were presented as the mean \pm standard error. Statistical analysis was performed using SPSS packed program version 10 (SPSS Inc., Chicago, IL, USA). $\mathrm{P}<0.05$ was considered to indicate a statistically significant result. Comparison of the non-parametric data among the groups was performed using the Mann-Whitney U test.

\section{Results}

8-Isoprostane levels. Following incubation with curcumin, bleomycin, bleomycin+curcumin, $\mathrm{H}_{2} \mathrm{O}_{2}$ or $\mathrm{H}_{2} \mathrm{O}_{2}+$ curcumin for $72 \mathrm{~h}$, cellular 8-isoPGF ${ }_{2 \alpha}$ levels were measured in NTera-2 and NCCIT cells. Incubation with bleomycin or $\mathrm{H}_{2} \mathrm{O}_{2}$ significantly increased 8-isoprostane levels in the two cell lines compared 


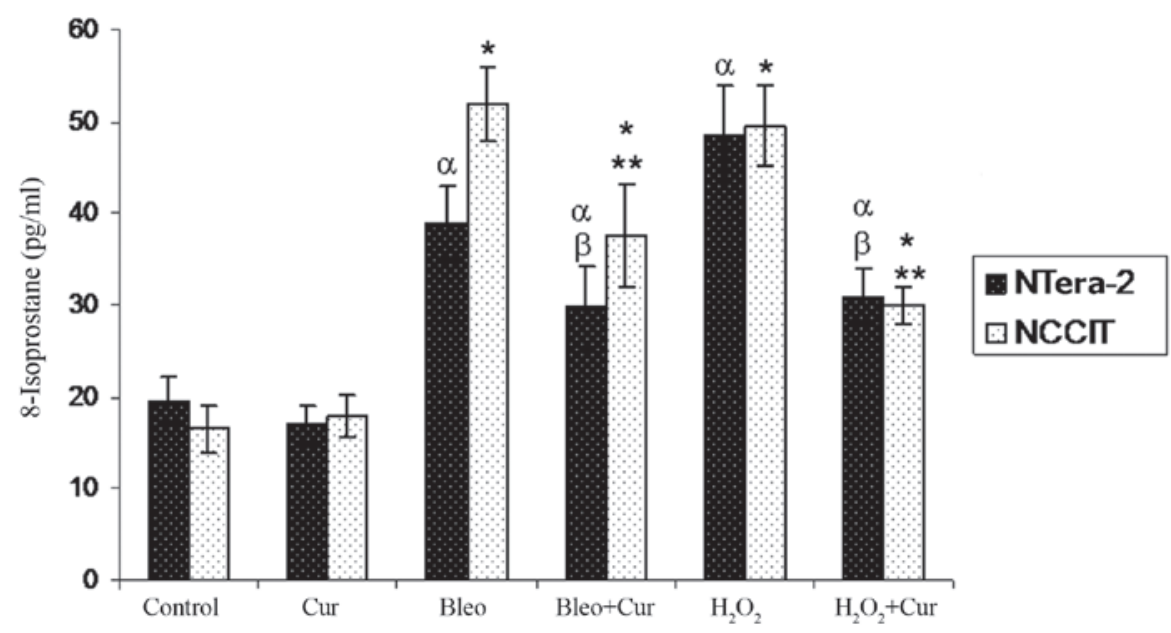

Figure 1. 8-Isoprostane levels in NTera-2 and NCCIT cells incubated with curcumin (Cur), bleomycin (Bleo), bleomycin+curcumin, $\mathrm{H}_{2} \mathrm{O}_{2}$, or $\mathrm{H}_{2} \mathrm{O}_{2}+$ curcumin for 72 h. ${ }^{\alpha} \mathrm{P}<0.02$ vs. NTera- 2 cells (control and incubated with curcumin); ${ }^{\beta} \mathrm{P}=0.03$ vs. NTera- 2 cells incubated with bleomycin or $\mathrm{H}_{2} \mathrm{O}_{2}$, respectively; ${ }^{*} \mathrm{P}<0.03$ vs. NCCIT cells (control and incubated with curcumin); ${ }^{* *} \mathrm{P}=0.01$ vs. NCCIT cells incubated with bleomycin or $\mathrm{H}_{2} \mathrm{O}_{2}$, respectively.

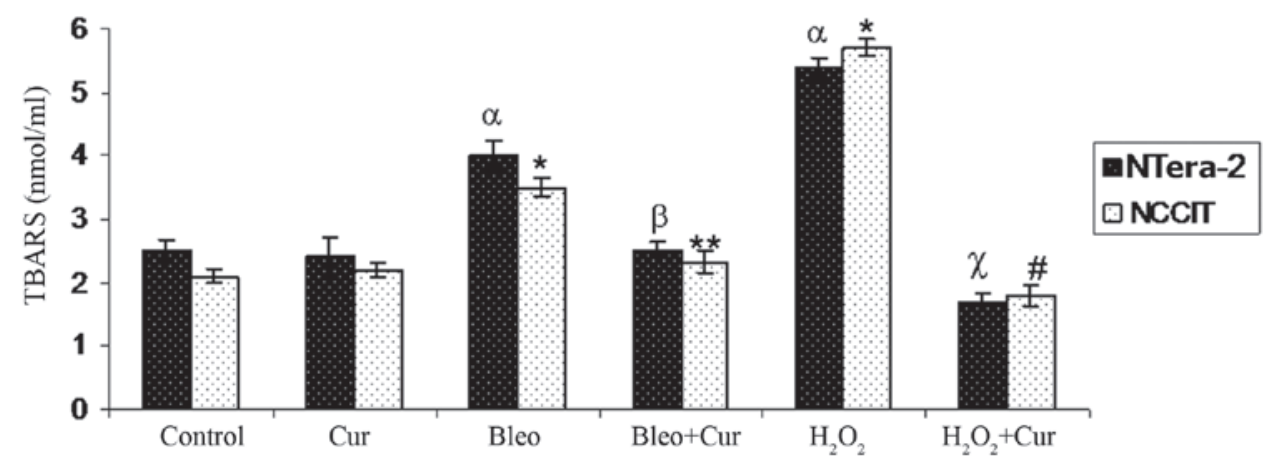

Figure 2. TBARS levels in NTera-2 and NCCIT cells incubated with curcumin (Cur), bleomycin (Bleo), bleomycin + curcumin, $\mathrm{H}_{2} \mathrm{O}_{2}$, or $\mathrm{H}_{2} \mathrm{O}_{2}+$ curcumin for $72 \mathrm{~h}$. ${ }^{\alpha} \mathrm{P}<0.04$ vs. control NTera- 2 cells; ${ }^{\beta} \mathrm{P}<0.03$ vs. NTera- 2 cells incubated with bleomycin; ${ }^{\circ} \mathrm{P}<0.01$ vs. NTera- 2 cells incubated with $\mathrm{H}_{2} \mathrm{O}_{2}$; ${ }^{*} \mathrm{P}<0.03$ vs. control NCCIT cells; ${ }^{* *} \mathrm{P}<0.03$ vs. NCCIT cells incubated with bleomycin; ${ }^{"} \mathrm{P}<0.03$ vs. NCCIT cells incubated with $\mathrm{H}_{2} \mathrm{O}_{2}$. TBARS, thiobarbituric acid reactive substances.

with the control cells and cells incubated with curcumin alone. Co-incubation of the two cell lines with bleomycin+curcumin or $\mathrm{H}_{2} \mathrm{O}_{2}+$ curcumin decreased 8-isoprostane levels significantly compared with the cells incubated with bleomycin or $\mathrm{H}_{2} \mathrm{O}_{2}$ alone, respectively (Fig. 1).

TBARS levels. TBARS levels were measured in NTera-2 and NCCIT cells following incubation with curcumin, bleomycin, bleomycin+curcumin, $\mathrm{H}_{2} \mathrm{O}_{2}$ or $\mathrm{H}_{2} \mathrm{O}_{2}+$ curcumin for $72 \mathrm{~h}$. TBARS levels were significantly increased in bleomycin and $\mathrm{H}_{2} \mathrm{O}_{2}$-treated groups when compared with the control cells. No significant difference was observed in TBARS levels measured in cells incubated with curcumin when compared with the control cells. Co-incubation of cells treated with bleomycin+curcumin or $\mathrm{H}_{2} \mathrm{O}_{2}$ +curcumin significantly reduced TBARS levels compared with the NTera-2 and NCCIT cells incubated with bleomycin or $\mathrm{H}_{2} \mathrm{O}_{2}$ alone, respectively (Fig. 2).

GSH levels. Cellular GSH levels were measured in NTera-2 and NCCIT cells following incubation with curcumin, bleomycin, bleomycin+curcumin, $\mathrm{H}_{2} \mathrm{O}_{2}$ or $\mathrm{H}_{2} \mathrm{O}_{2}+$ curcumin for
72 h. GSH levels were not significantly different in NTera-2 cells incubated with curcumin compared with control NTera-2 cells. Bleomycin, $\mathrm{H}_{2} \mathrm{O}_{2}$ or $\mathrm{H}_{2} \mathrm{O}_{2}+$ curcumin significantly reduced GSH levels in NTera-2 cells compared with the control NTera-2 cells. Co-incubation with curcumin and bleomycin did not significantly increase GSH levels in NTera-2 cells compared with the NTera-2 cells incubated with bleomycin alone. GSH levels were significantly lower in NCCIT cells incubated with curcumin, bleomycin, bleomycin+curcumin, $\mathrm{H}_{2} \mathrm{O}_{2}$ or $\mathrm{H}_{2} \mathrm{O}_{2}+$ curcumin compared with the control NCCIT cells (Fig. 3).

Protein carbonyl levels. Protein carbonyl content was measured in NTera-2 and NCCIT cells following incubation with curcumin, bleomycin, bleomycin+curcumin, $\mathrm{H}_{2} \mathrm{O}_{2}$ or $\mathrm{H}_{2} \mathrm{O}_{2}+$ curcumin for $72 \mathrm{~h}$. Curcumin decreased the protein carbonyl level significantly in NCCIT cells, but not significantly in NTera-2 cells compared with the control cells and other cell groups. The lowest significant protein carbonyl level was found in NCCIT cells incubated with curcumin. The protein carbonyl level increased in the two cell lines incubated with bleomycin or $\mathrm{H}_{2} \mathrm{O}_{2}$. The protein carbonyl content 


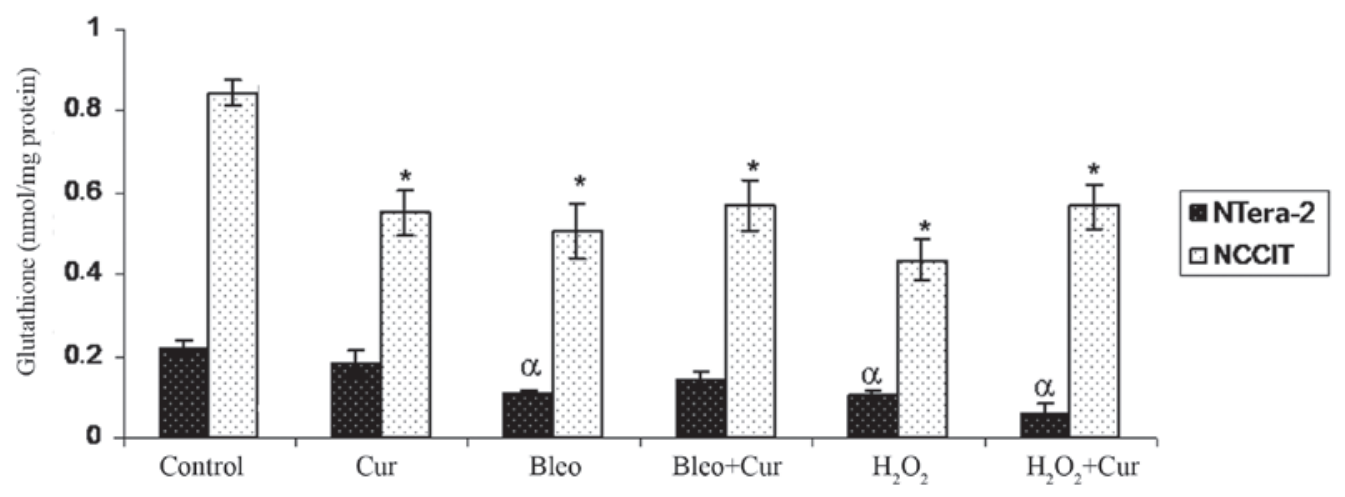

Figure 3. GSH levels in NTera-2 and NCCIT cells incubated with curcumin (Cur), bleomycin (Bleo), bleomycin+curcumin, $\mathrm{H}_{2} \mathrm{O}_{2}$ or $\mathrm{H}_{2} \mathrm{O}_{2}+$ curcumin for $72 \mathrm{~h}$. ${ }^{a} \mathrm{P}<0.03$ vs. control NTera-2 cells; $\mathrm{P}<0.006$ vs. control NCCIT cells. GSH, glutathione.

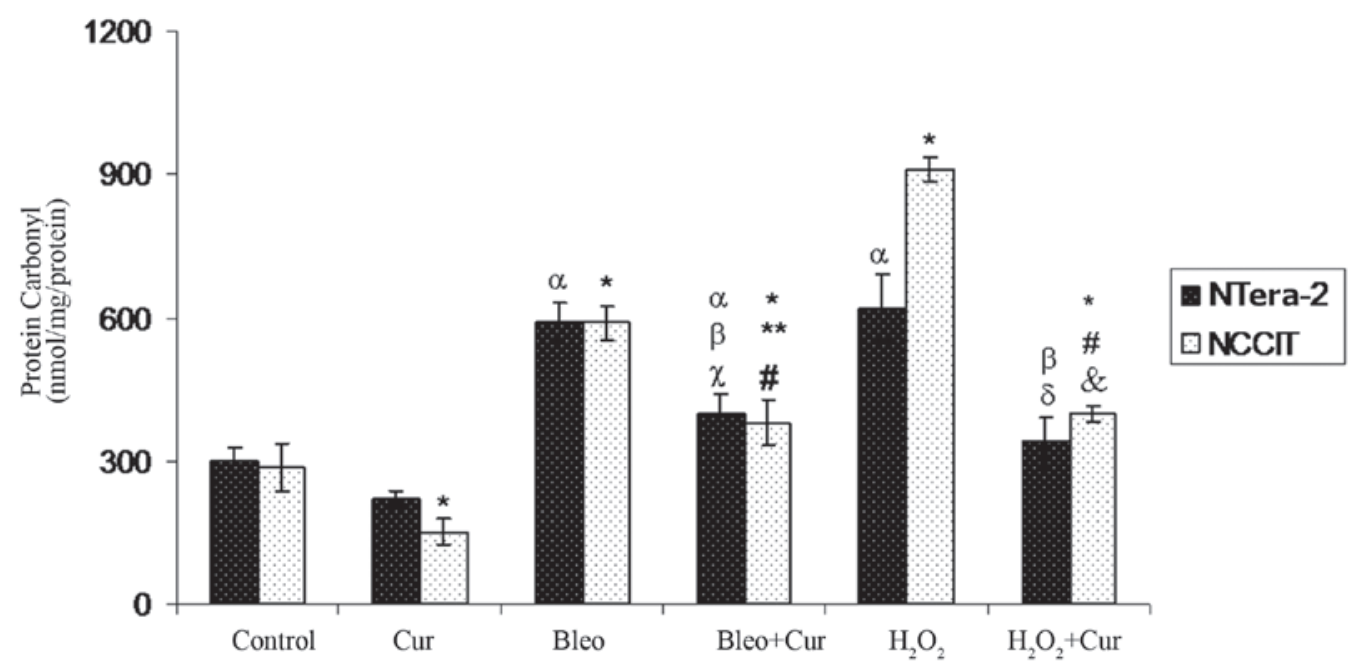

Figure 4. Protein carbonyl levels in NTera-2 and NCCIT cells incubated with curcumin (Cur), bleomycin (Bleo), bleomycin + curcumin, $\mathrm{H}_{2} \mathrm{O}_{2}$ or $\mathrm{H}_{2} \mathrm{O}_{2}+$ curcumin for $72 \mathrm{~h} .{ }^{\alpha} \mathrm{P}<0.04$ vs. NTera-2 cells (control and cells incubated with curcumin); ${ }^{\beta} \mathrm{P}<0.03$ vs. NTera- 2 cells incubated with curcumin; ${ }^{\times} \mathrm{P}<0.01$ vs. NTera- 2 cells incubated with bleomycin; ${ }^{\circ} \mathrm{P}<0.01$ vs. NTera- 2 cells incubated with $\mathrm{H}_{2} \mathrm{O}_{2} ;{ }^{*} \mathrm{P}<0.04$ vs. control NCCIT cells; ${ }^{* *} \mathrm{P}<0.01$ vs. NCCIT cells incubated with bleomycin; ${ }^{\sharp} \mathrm{P}<0.01$ vs. NCCIT cells incubated with curcumin; ${ }^{\circledR} \mathrm{P}<0.01$ vs. NCCIT cells incubated with $\mathrm{H}_{2} \mathrm{O}_{2}$.

was double (600 nmol/mg) in NTera-2 cells incubated with bleomycin compared with the level $(300 \mathrm{nmol} / \mathrm{mg})$ in control NTera-2 cells. Compared with control NCCIT cells, NCCIT cells incubated with $\mathrm{H}_{2} \mathrm{O}_{2}$ showed a 3-fold increase in protein carbonyl content. Co-incubation with curcumin and bleomycin or curcumin and $\mathrm{H}_{2} \mathrm{O}_{2}$ significantly decreased protein carbonyl content in the two cell lines incubated with bleomycin or $\mathrm{H}_{2} \mathrm{O}_{2}$ alone, respectively (Fig. 4).

Antioxidant capacity levels. Antioxidant capacity increased significantly in NTera-2 cells incubated with curcumin in comparison with the untreated NTera- 2 cells. The highest significant antioxidant capacity level was found in NTera-2 cells incubated with curcumin. By contrast, NTera- 2 cells incubated with bleomycin or $\mathrm{H}_{2} \mathrm{O}_{2}$ exhibited a significant decrease in antioxidant levels compared with the control NTera-2 cells. However, co-incubation of NTera-2 cells with curcumin and bleomycin or curcumin and $\mathrm{H}_{2} \mathrm{O}_{2}$ significantly increased antioxidant levels compared with NTera-2 cells incubated with bleomycin or $\mathrm{H}_{2} \mathrm{O}_{2}$ alone, respectively. No significant difference was observed in the antioxidant levels in the NCCIT cells incubated with different agents compared with the control NCCIT cells (Fig. 5).

LPO levels. Curcumin treatment significantly reduced LPO levels in the two cell lines compared with the control cells. Incubation with bleomycin or $\mathrm{H}_{2} \mathrm{O}_{2}$ in the two cell lines caused a significant increase in LPO levels compared with the control cells. However, co-incubation with curcumin and bleomycin or curcumin and $\mathrm{H}_{2} \mathrm{O}_{2}$ significantly decreased LPO levels in the two cells compared with the cells incubated with bleomycin or $\mathrm{H}_{2} \mathrm{O}_{2}$ alone, respectively (Fig. 6).

\section{Discussion}

Curcumin is currently being evaluated as a potential chemotherapeutic agent in several clinical trials $(16,17)$. Animal studies have shown that curcumin prevents carcinogenesis in the colon (18) and breast (19). Curcumin exhibits potent in vitro antiproliferative and apoptosis-inducing activities in a range of human cancer cell lines, including those derived from cancers of the prostate, breast, ovary and colon (20-22), 


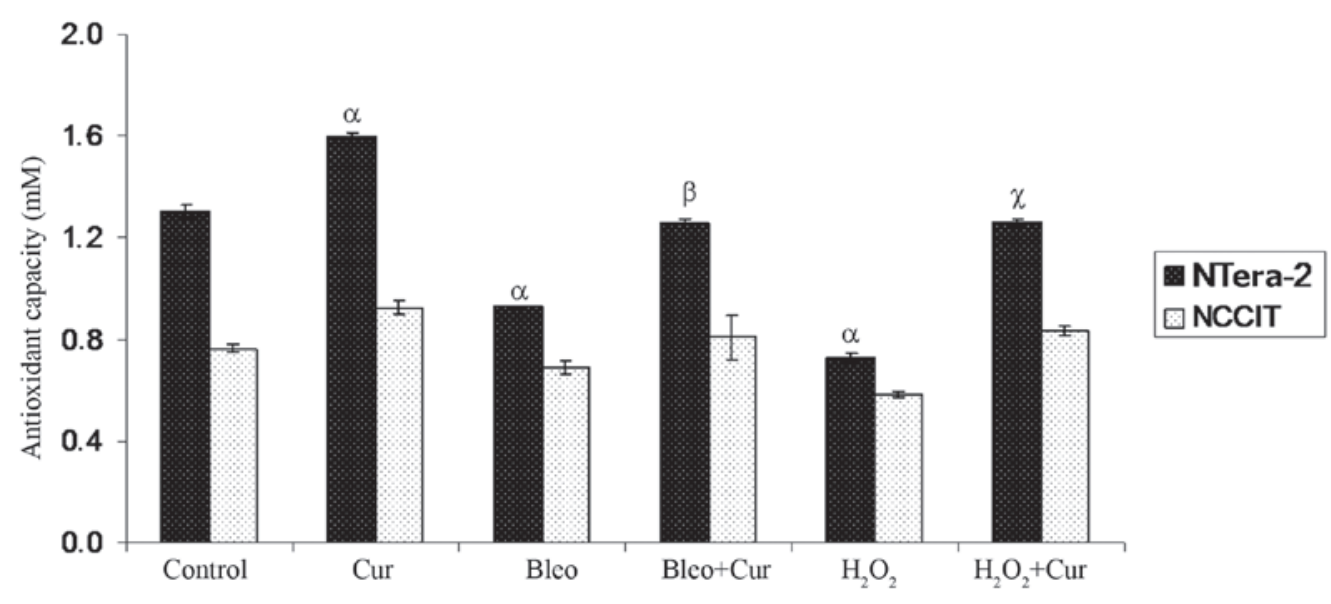

Figure 5. Antioxidant capacity in NTera-2 and NCCIT cells incubated with curcumin (Cur), bleomycin (Bleo), bleomycin+curcumin, $\mathrm{H}_{2} \mathrm{O}_{2}$ or $\mathrm{H}_{2} \mathrm{O}_{2}+$ curcumin for 72 h. ${ }^{\alpha} \mathrm{P}<0.03$ vs. control NTera- 2 cells; ${ }^{\beta} \mathrm{P}<0.03$ vs. NTera- 2 cells incubated with bleomycin; ${ }^{\times} \mathrm{P}<0.03$ vs. NTera-2 cells incubated with $\mathrm{H}_{2} \mathrm{O}_{2}$.

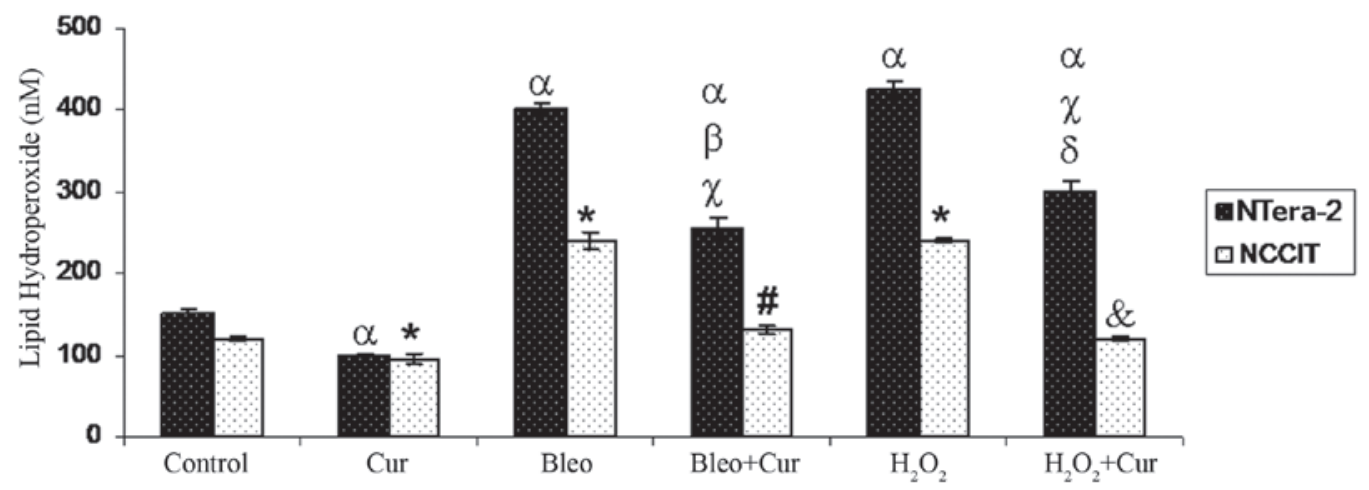

Figure 6. LPO levels in NTera-2 and NCCIT cells incubated with curcumin (Cur), bleomycin (Bleo), bleomycin+curcumin, $\mathrm{H}_{2} \mathrm{O}_{2}$ or $\mathrm{H}_{2} \mathrm{O}_{2}+$ curcumin for $72 \mathrm{~h}$. ${ }^{a} \mathrm{P}<0.03$ vs. control NTera- 2 cells; ${ }^{\beta} \mathrm{P}<0.03$ vs. NTera- 2 cells incubated with bleomycin; ${ }^{\circ} \mathrm{P}<0.03$ vs. NTera- 2 cells incubated with curcumin; ${ }^{\circ} \mathrm{P}<0.03$ vs. NTera- 2 cells incubated with $\mathrm{H}_{2} \mathrm{O}_{2} ;{ }^{*} \mathrm{P}<0.003$ vs. control NCCIT cells; ${ }^{*} \mathrm{P}<0.001$ vs. NCCIT cells incubated with bleomycin; ${ }^{\circledR} \mathrm{P}<0.001$ vs. NCCIT cells incubated with $\mathrm{H}_{2} \mathrm{O}_{2}$. LPO, lipid hydroperoxide.

but no study has been carried out with regard to the effects of curcumin on oxidative stress in testicular cancer cells.

We used a curcumin concentration in our experiments relevant to the antioxidant (curcumin) uptake concentration in humans. There are conflicting studies in the literature with regard to the oral intake of curcumin and its serum and urine concentrations. Evidence suggests that orally administered curcumin accumulates in gastrointestinal tissues. For instance, when colorectal cancer patients were administered $3.6 \mathrm{~g} /$ day of curcumin orally for seven days prior to surgery, curcumin was detected in malignant and normal colorectal tissue (23). By contrast, curcumin was not detected in the liver tissue of patients with liver metastases of colorectal cancer following the same oral dose of curcumin (24), suggesting that oral curcumin administration may not effectively deliver curcumin to tissues outside the gastrointestinal tract. Results of a clinical study (25) have shown that no curcumin was detected in the serum of participants administered with 500; 1,000; 2,000; 4,$000 ; 6,000$ or $8,000 \mathrm{mg}$ curcumin. The presence of curcumin was only detected in two subjects (one receiving $10,000 \mathrm{mg}$ and one receiving $12,000 \mathrm{mg}$ ). No plasma concentrations of curcumin were detected in the remaining subjects receiving 10,000 or $12,000 \mathrm{mg}$ dose levels. By contrast, in a clinical trial conducted in Taiwan, the serum concentration of curcumin was usually found to peak at $1-2 \mathrm{~h}$ following oral intake of curcumin and gradually declined within $12 \mathrm{~h}$ (26). The average peak serum concentrations following the administration of 4,$000 ; 6,000$ and $8,000 \mathrm{mg}$ curcumin were $0.51 \pm 0.11$, $0.63 \pm 0.06$ and $1.77 \pm 1.87 \mu \mathrm{M}$, respectively. Urinary excretion of curcumin was undetectable. We incubated two types of testicular cancer cells with various concentrations of curcumin and selected the doses of $20 \mu \mathrm{M}$ for NTera- 2 cells and $5 \mu \mathrm{M}$ for NCCIT cells. These doses were higher than the doses used in the study in Taiwan (26). The reason for using higher curcumin doses in our study was that other investigators (25) did not detect curcumin in serum with the same doses used by the investigators in Taiwan (26). To eliminate these conflicting results, we selected effective curcumin concentrations based on our previous experimental results (15).

Our data revealed that bleomycin and $\mathrm{H}_{2} \mathrm{O}_{2}$ significantly increased 8-isoprostane, protein carbonyl, TBARS and LPO levels in the two cell types and significantly decreased antioxidant capacity and GSH levels in NTera-2 cells. Incubation with bleomycin or $\mathrm{H}_{2} \mathrm{O}_{2}$ did not affect antioxidant capacity, but significantly decreased GSH levels in NCCIT cells. Previous studies have reported that bleomycin catalyzes the 
formation of ROS with ultimate progression to lipid peroxidation (27). This effect is likely a secondary event, following bleomycin-induced increase in free radical generation. Quantification of lipid peroxidation is essential to assess the role of oxidative injury in cancer. The increase in lipid peroxidation via bleomycin and the suppressive effect of curcumin were demonstrated by Venkatesan et al in rat lung injury (28). This is the first study showing the suppressive effect of curcumin on bleomycin and $\mathrm{H}_{2} \mathrm{O}_{2}$-induced increases in LPO levels in testicular cancer cells. 8-Isoprostane is a reliable marker of oxidative stress. Bleomycin and $\mathrm{H}_{2} \mathrm{O}_{2}$ significantly increased 8-isoprostane levels in NTera-2 and NCCIT cells. Increases in 8-isoPGF ${ }_{2 \alpha}$ levels as a function of bleomycin and $\mathrm{H}_{2} \mathrm{O}_{2}$ exposure have not been previously reported in testicular cancer cells. Co-incubation with curcumin significantly decreased 8-isoprostane levels in the two cell lines incubated with bleomycin and $\mathrm{H}_{2} \mathrm{O}_{2}$. Similar to our findings, curcumin was reported to induce a decrease in 8-iso-prostaglandin levels following exposure to radiation in breast cancer cells (29). The measurement of TBARS is a well-established method for screening and monitoring lipid peroxidation. In the present study, we demonstrated that bleomycin and $\mathrm{H}_{2} \mathrm{O}_{2}$ increased TBARS levels in the two cell lines compared with the control cells. Co-incubation of curcumin with bleomycin or $\mathrm{H}_{2} \mathrm{O}_{2}$ decreased TBARS levels compared with the cells incubated with bleomycin or $\mathrm{H}_{2} \mathrm{O}_{2}$ alone. Increased TBARS formation was reported in human hepatoma $\mathrm{G} 2$ cells following exposure to high levels of curcumin. By contrast, exposure to low curcumin concentration did not cause any increase in TBARS levels, similar to our findings (30).

The most general indicator and by far the most commonly used marker of protein oxidation is protein carbonyl content, based on the fact that free radicals convert amino acid side chains to carbonyl moieties in vitro. In our study, we used the method of protein 2,4-DNPH post labeling, originally introduced by Levine et al (31), for isolated proteins as a useful monitor of bleomycin and $\mathrm{H}_{2} \mathrm{O}_{2}$-mediated oxidative protein damage. Our data clearly demonstrate that curcumin treatment inhibits bleomycin and $\mathrm{H}_{2} \mathrm{O}_{2}$-induced protein oxidation as monitored by measuring the formation of protein reactive carbonyl contents in testicular cancer cells and provides further indication that curcumin protects cancer cells from oxidative stress via its antioxidant property. Bleomycin or $\mathrm{H}_{2} \mathrm{O}_{2}$-mediated increases in protein carbonyl content likely indicates a predisposition of testicular cancer cells to cell death. Biswas et al showed that curcumin did not have a significant effect on protein carbonyl content in arsenic carcinogenicity in humans (32). By contrast, Dance-Barnes et al reported that curcumin increased oxidative damage in mouse lung tissue by inducing protein carbonylation (33). In another study performed by Biswas et al, curcumin treatment reduced ROS generation, lipid peroxidation and protein carbonyl content, which were elevated by arsenic in Swiss albino mice (34). Bleomycin and $\mathrm{H}_{2} \mathrm{O}_{2}$ significantly decreased GSH levels in NTera-2 cells. Bleomycin, $\mathrm{H}_{2} \mathrm{O}_{2}$, curcumin, bleomycin+curcumin or $\mathrm{H}_{2} \mathrm{O}_{2}+$ curcumin led to a decrease in GSH levels in NCCIT cells. The curcumin-induced depletion of GSH was demonstrated in previous studies $(35,36)$. Hilchie et al reported that the curcumin treatment of prostate cancer cells caused depletion of GSH. The authors reported that GSH depletion was not due to curcumin-induced ROS production (35). Curcumin-GSH interactions were demonstrated in another study performed by Awasthi et al (37). Previously, it was found that GSH S-transferase catalyzes a reaction between curcumin and GSH in Caco-2 colon cancer cells, leading to the formation of monoglutathionyl curcumin conjugates (38). The antioxidant capacity is a measure of total protective antioxidant mechanisms both for preventing the production of free radicals and for repairing oxidative damage (39). Curcumin has been shown to have beneficial effects on the antioxidant defense system, scavenge free radicals and/or prevent lipid peroxidation and it is at least 10 times more active as an antioxidant than vitamin E. In our study, bleomycin and $\mathrm{H}_{2} \mathrm{O}_{2}$ decreased total antioxidant capacity in the two testicular cancer cell lines but incubation with curcumin enhanced total antioxidant capacity. Anti-carcinogenic action of curcumin by activation of antioxidant defence system was reported in animal models and cell lines $(29,40)$. This is the first study showing that curcumin has an inhibitory effect on bleomycin and $\mathrm{H}_{2} \mathrm{O}_{2}$-induced oxidative stress.

The probability that antioxidants interfere with the conventional cancer treatments, which are designed to prevent the mortality of cancer patients, is a complex issue. Although numerous chemotherapy drugs induce the formation of ROS, their anticancer effects do not, in general, depend on the formation of these free radicals. Antioxidant supplementation may in certain circumstances aid the prevention of free-radical-induced side effects without inhibiting the positive effects of the chemotherapy and provide a safe and effective means of enhancing the response to cancer chemotherapy. The cancer cells should divide rapidly for the cytotoxic effect of anticancer agents. Excess ROS in cancer cells slows or arrests cell growth and interferes with the effectiveness of chemotherapy since anticancer drugs are effective only when there is rapid cell proliferation. Antioxidant supplementation during chemotherapy may overcome the growth-inhibiting effects of oxidative stress and maintain responsiveness to antineoplastic agents $(12,13)$. Our findings with curcumin supports these hypotheses. We found that curcumin decreases oxidative stress in germ cells induced by bleomycin, however, this does not mean that curcumin decreases the chemotherapeutic effect of bleomycin. By decreasing oxidative stress, curcumin may increase the response to bleomycin since bleomycin does not exert its chemotherapeutic action only by generating oxidative stress. Our results demonstrate the precise molecular pathways of the inhibitory effect of curcumin on oxidative stress in human testicular cancer cells induced by bleomycin. Although curcumin decreased oxidative stress in germ cells induced by bleomycin, this does not mean that curcumin decreases the chemotherapeutic effect of bleomycin. By contrast, by decreasing oxidative stress, curcumin may increase the response to bleomycin. It can be concluded that curcumin has certain inhibitory effects on oxidative stress and its concomitant use with bleomycin should be followed closely during the treatment of testicular cancer.

\section{Acknowledgements}

This study was supported by TUBITAK, Turkey (COSTCM0603-15; 107S291) and Akdeniz University. 


\section{References}

1. Chieffi P: New prognostic markers and potential therapeutic targets in human testicular germ cell tumors. Curr Med Chem 18: 5033-5040, 2011.

2. de Wit R, Stoter G, Kaye SB, et al: Importance of bleomycin in combination chemotherapy for good-prognosis testicular nonseminoma: a randomized study of the European Organization for Research and Treatment of Cancer Genitourinary Tract Cancer Cooperative Group. J Clin Oncol 15: 1837-1843, 1997.

3. Burger RM, Peisach J and Horwitz SB: Activated bleomycin. A transient complex of drug, iron, and oxygen that degrades DNA. J Biol Chem 256: 11636-11644, 1981.

4. Yen CY, Chiu CC, Haung RW, et al: Antiproliferative effects of goniothalamin on Ca9-22 oral cancer cells through apoptosis, DNA damage and ROS induction. Mutat Res 747: 253-258, 2012.

5. Ullah MF, Ahmad A, Zubair H, et al: Soy isoflavone genistein induces cell death in breast cancer cells through mobilization of endogenous copper ions and generation of reactive oxygen species. Mol Nutr Food Res 55: 553-559, 2011.

6. Yu JS and Kim AK: Wogonin induces apoptosis by activation of ERK and p38 MAPKs signaling pathways and generation of reactive oxygen species in human breast cancer cells. Mol Cells 31: 327-335, 2011.

7. Conklin KA: Cancer chemotherapy and antioxidants. J Nutr 134: 3201S-3204S, 2004.

8. Nakamura $\mathrm{H}$, Nakamura $\mathrm{K}$ and Yodoi J: Redox regulation of cellular activation. Annu Rev Immunol 15: 351-369, 1997.

9. Cantoni O, Cattabeni F, Stocchi V, Meyn RE, Cerutti P and Murray D: Hydrogen peroxide insult in cultured mammalian cells: relationships between DNA single-strand breakage, poly(ADP-ribose) metabolism and cell killing. Biochim Biophys Acta 1014: 1-7, 1989.

10. Kim KY, Yu SN, Lee SY, et al: Salinomycin-induced apoptosis of human prostate cancer cells due to accumulated reactive oxygen species and mitochondrial membrane depolarization. Biochem Biophys Res Commun 413: 80-86, 2011.

11. Bejarano I, Espino J, Marchena AM, et al: Melatonin enhances hydrogen peroxide-induced apoptosis in human promyelocytic leukaemia HL-60 cells. Mol Cell Biochem 353: 167-176, 2011.

12. Ozben T: Oxidative stress and apoptosis: impact on cancer therapy. J Pharm Sci 96: 2181-2196, 2007.

13. Akbas HS, Timur M and Ozben T: Concurrent use of antioxidants in cancer therapy: an update. Expert Rev Clin Immunol 2: 931-939, 2006.

14. Duvoix A, Blasius R, Delhalle S, et al: Chemopreventive and therapeutic effects of curcumin. Cancer Lett 223: 181-190, 2005.

15. Cort A, Timur M, Ozdemir E, Kucuksayan E and Ozben T: Synergistic anticancer activity of curcumin and bleomycin: An in vitro study using human malignant testicular germ cells. Mol Med Rep 5: 1481-1486, 2012.

16. Thomasset SC, Berry DP, Garcea G, Marczylo T, Steward WP and Gescher AJ: Dietary polyphenolic phytochemicals - promising cancer chemopreventive agents in humans? A review of their clinical properties. Int J Cancer 120: 451-458, 2007.

17. Strimpakos AS and Sharma RA: Curcumin: preventive and therapeutic properties in laboratory studies and clinical trials. Antioxid Redox Signal 10: 511-545, 2008.

18. Xu G, Ren G, Xu X, et al: Combination of curcumin and green tea catechins prevents dimethylhydrazine-induced colon carcinogenesis. Food Chem Toxicol 48: 390-395, 2010.

19. Bachmeier B, Nerlich AG, Iancu CM, et al: The chemopreventive polyphenol Curcumin prevents hematogenous breast cancer metastases in immunodeficient mice. Cell Physiol Biochem 19: $137-152,2007$.

20. Watson JL, Hill R, Yaffe PB, et al: Curcumin causes superoxide anion production and p53-independent apoptosis in human colon cancer cells. Cancer Lett 297: 1-8, 2010.

21. Watson JL, Greenshields A, Hill R, et al: Curcumin-induced apoptosis in ovarian carcinoma cells is p53-independent and involves p38 mitogen-activated protein kinase activation and downregulation of $\mathrm{Bcl}-2$ and survivin expression and $\mathrm{Akt}$ signaling. Mol Carcinog 49: 13-24, 2010.
22. Aggarwal BB, Banerjee S, Bharadwaj U, Sung B, Shishodia S and Sethi G: Curcumin induces the degradation of cyclin E expression through ubiquitin-dependent pathway and up-regulates cyclindependent kinase inhibitors p21 and p27 in multiple human tumor cell lines. Biochem Pharmacol 73: 1024-1032, 2007.

23. Garcea G, Berry DP, Jones DJ, et al: Consumption of the putative chemopreventive agent curcumin by cancer patients: assessment of curcumin levels in the colorectum and their pharmacodynamic consequences. Cancer Epidemiol Biomarkers Prev 14: 120-125, 2005.

24. Garcea G, Jones DJ, Singh R, et al: Detection of curcumin and its metabolites in hepatic tissue and portal blood of patients following oral administration. Br J Cancer 90: 1011-1015, 2004.

25. Lao CD, Ruffin MT IV, Normolle D, et al: Dose escalation of a curcuminoid formulation. BMC Complement Altern Med 6: 10, 2006.

26. Cheng AL, Hsu CH, Lin JK, et al: Phase I clinical trial of curcumin, a chemopreventive agent, in patients with high-risk or pre-malignant lesions. Anticancer Res 21: 2895-2900, 2001

27. Ali EN and Mansour SZ: Boswellic acids extract attenuates pulmonary fibrosis induced by bleomycin and oxidative stress from gamma irradiation in rats. Chin Med 6: 36, 2011.

28. Venkatesan N, Punithavathi V and Chandrakasan G: Curcumin protects bleomycin-induced lung injury in rats. Life Sci 61: PL51-PL58, 1997.

29. Calaf GM, Echiburú-Chau C, Roy D, Chai Y, Wen G and Balajee AS: Protective role of curcumin in oxidative stress of breast cells. Oncol Rep 26: 1029-1035, 2011.

30. Cao J, Jia L, Zhou HM, Liu Y and Zhong LF: Mitochondrial and nuclear DNA damage induced by curcumin in human hepatoma G2 cells. Toxicol Sci 91: 476-483, 2006.

31. Levine RL, Williams JA, Stadtman ER and Shacter E: Carbonyl assays for determination of oxidatively modified proteins. Methods Enzymol 233: 346-357, 1994

32. Biswas J, Sinha D, Mukherjee S, Roy S, Siddiqi M and Roy M: Curcumin protects DNA damage in a chronically arsenicexposed population of West Bengal. Hum Exp Toxicol 29: 513-524, 2010.

33. Dance-Barnes ST, Kock ND, Moore JE, et al: Lung tumor promotion by curcumin. Carcinogenesis 30: 1016-1023, 2009.

34. Biswas J, Roy S, Mukherjee S, Sinha D and Roy M: Indian spice curcumin may be an effective strategy to combat the genotoxicity of arsenic in Swiss albino mice. Asian Pac J Cancer Prev 11: 239-247, 2010.

35. Hilchie AL, Furlong SJ, Sutton K, et al: Curcumin-induced apoptosis in PC3 prostate carcinoma cells is caspase-independent and involves cellular ceramide accumulation and damage to mitochondria. Nutr Cancer 62: 379-389, 2010.

36. Atsumi T, Tonosaki K and Fujisawa S: Comparative cytotoxicity and ROS generation by curcumin and tetrahydrocurcumin following visible-light irradiation or treatment with horseradish peroxidase. Anticancer Res 27: 363-371, 2007.

37. Awasthi S, Pandya U, Singhal SS, et al: Curcumin-glutathione interactions and the role of human glutathione S-transferase P1-1. Chem Biol Interact 128: 19-38, 2000.

38. Usta M, Wortelboer HM, Vervoort J, et al: Human glutathione S-transferase-mediated glutathione conjugation of curcumin and efflux of these conjugates in Caco-2 cells. Chem Res Toxicol 20: 1895-1902, 2007.

39. Koracevic D, Koracevic G, Djordjevic V, Andrejevic S and Cosic V: Method for the measurement of antioxidant activity in human fluids. J Clin Pathol 54: 356-361, 2001.

40. Das L and Vinayak M: Anti-carcinogenic action of curcumin by activation of antioxidant defence system and inhibition of NF- $\kappa \mathrm{B}$ signalling in lymphoma-bearing mice. Biosci Rep 32: 161-170, 2012. 